\title{
"HEI DE CUMPRIR ESSES MEOS DEVERES DA MILHOR FORMA POSSIVEL": indícios da presença italiana em São Paulo a partir do processo disciplinar contra professor público (Brotas, 1895/1896)
}

"I WILL COMPLY WITH THESE DUTIES IN THE MOST POSSIBLE FORM":
evidence of the Italian presence in São Paulo from a disciplinaty process against a public teacher (Brotas, 1895/1896)

\author{
Claudia Panizzolo \\ Doutora em Educação \\ Universidade Federal de São Paulo- UNIFESP \\ Guarulhos, SP- Brasil \\ claudia.panizzolo@unifesp.br \\ iD Gabriel Meneses Barros \\ Mestre em Educação \\ Universidade Federal de São Paulo - Unifesp \\ São Paulo, SP - Brasil \\ gabrielmbarros@uol.com.br \\ (iD) \\ Andrea de Faria Souza \\ Mestranda em Educação \\ Universidade Federal de São Paulo - UNIFESP \\ São Paulo, SP - Brasil \\ andreafariasouza75@gmail.com
}

Resumo: Em 1895 foi iniciado um processo contra Luigi Pericles Salmena, de nacionalidade italiana, que atuava como professor interino, em uma escola provisória na cidade de Brotas, interior do Estado de São Paulo. Este artigo tem por objetivo problematizar o exercício da docência pelo imigrante, valendo-se de um caso de processo disciplinar da Instrução Pública Paulista. Interroga-se assim, qual o lugar da docência nas pesquisas sobre história da imigração italiana em São Paulo. Ancorado nos referenciais da História Cultural e da História da Educação e tendo a análise documental como procedimento adotado, tem como fontes o processo disciplinar, leis, decretos e a imprensa local. Toma-se de empréstimo a conceituação de tática e estratégia de De Certeau (2014). Como conclusão têm-se as disputas de poder entre as Câmaras Municipais e os inspetores de distrito; bem como a inserção do imigrante italiano na Instrução Pública desde fins do século XIX.

Palavras-chave: Imigração italiana. Processo disciplinar. Professor italiano. Tática. Inspetor de distrito.

Abstract: In 1895, a lawsuit was initiated against Luigi Pericles Salmena, an Italian citizen who worked as an interim teacher, in a temporary school in the city of Brotas, State of São Paulo. This article aims to problematize the exercise of teaching by the immigrant, using a case of disciplinary proceedings from the São Paulo Public Instruction. It is therefore questioned, what is the place of teaching in research on the History of Italian immigration in São Paulo. Anchored in the references of Cultural History and the History of Education and having documentary analysis as the adopted procedure, its sources are the disciplinary process, laws, and the local press. De Certeau's concept of tactics and strategy (2014) is borrowed. As a conclusion, there are the power disputes between the City Councils and the district inspectors; as well as the insertion of the Italian immigrant in Public Education since the end of the 19th century.

Key-words: Italian immigration. Disciplinary proceedings. Italian teacher. Tactic. District inspector.

Cite como

\section{(ABNT NBR 6023:2018)}

PANIZZOLO, Claudia; BARROS, Gabriel Meneses; SOUZA, Andrea de Faria. "Hei de cumprir esses meos deveres da milhor forma possivel": indícios da presença italiana em são paulo a partir do processo disciplinar contra professor público (brotas, 1895/1896). Dialogia, São Paulo, n. 37, p. 1-13, e19721, jan./abr. 2021. Disponível em: https://doi.org/10.5585/dialogia.n37.19721

American Psychological Association (APA)

Panizzolo, C., Barros, G. M., \& Souza, A. de. F. (2021, jan./abr.). "Hei de cumprir esses meos deveres da milhor forma possivel”: indícios da presença italiana em são paulo a partir do processo disciplinar contra professor público (brotas, 1895/1896). Dialogia, São Paulo, 37, p. 1-13, e19721. https://doi.org/10.5585/dialogia.n37.19721 
PANIZZOLO, Claudia; BARROS, Gabriel Meneses; SOUZA, Andrea de Faria. "Hei de cumprir esses meos deveres da milhor forma possivel": indícios da presença italiana em são paulo a partir do processo disciplinar contra professor público (Brotas, 1895/1896)

\section{Introdução}

Os anos compreendidos entre 1870 e 1890 comportaram a crise da economia mercantilescravista, a substituição do trabalhador escravo pelo livre e a mudança do regime políticoadministrativo. A decadência das lavouras tradicionais e o desenvolvimento paralelo do café durante a segunda metade do século XIX deslocam a primazia econômica do país do Nordeste para o Centro-Sul. O Oeste Paulista, região mais recente das plantações, começa a substituir em importância o Vale do Paraíba, região ocupada na primeira fase da expansão cafeeira, agora em decadência, entre outros motivos, pela diminuição da oferta de mão-de-obra, além do uso impróprio do solo (COSTA, 1999).

A aceleração do processo de acumulação de capitais na cafeicultura traz no seu bojo a ferrovia e a política imigratória, que soluciona o grave problema da mão-de-obra para a agricultura. A exportação do café precisava continuar, o mercado internacional demandava e as terras roxas do interior de São Paulo eram cada vez mais ocupadas. A riqueza e o progresso do país dependiam prioritariamente do café. O governo passa a estimular e subsidiar, juntamente com os fazendeiros, a vinda de imigrantes cujo destino seriam as fazendas de café. Após algumas experiências ${ }^{1}$, e com a proibição do tráfego negreiro, institucionaliza-se, a partir de 1870, uma política imigratória que, no entanto, só tomaria impulso após a abolição da escravatura e cujos números permitem vislumbrar o impacto que provoca:

De 1882 a 1886, o número de imigrantes que chegava por ano era - em média - inferior a 6 mil. Com o estabelecimento da Sociedade Promotora da Imigração, só no ano de 1887 chegaram 32 mil e, em 1888, vieram 92 mil. Isso era só o começo, pois de 1889 ao início do século, 750 mil estrangeiros desembarcaram em São Paulo, dos quais cerca de $80 \%$ subsidiados pelo governo. A grande maioria era de italianos; em menor número, espanhóis e portugueses, e, por fim, franceses, ingleses, alemães, sírios, libaneses, russos e outros. De 1893 a 1900, partiram da Hospedaria dos Imigrantes na capital, rumo ao interior do estado, 323.154 trabalhadores (COSTA, 1999, p. 36).

A maioria dos imigrantes que entra no Brasil nesse período é encaminhada para as lavouras de café, para exercer funções antes desempenhadas pelos escravizados. No caso específico de São Paulo, assim que podem, os imigrantes abandonam as lavouras onde vivem em condições precárias. Alguns desiludidos voltam à sua pátria; outros migram para outras áreas. Alguns, no entanto, localizam-se em núcleos urbanos, dedicando-se ao comércio, ao artesanato, às manufaturas e aos pequenos serviços. É preciso ainda destacar que nem todos vão para a lavoura: muitos imigrantes

\footnotetext{
${ }^{1}$ Como exemplo pode-se citar as Colônias Nova Louzã e Nova Colômbia - ambas de propriedade de João Elisário de Carvalho Montenegro. Consideradas à época como modelares, implementaram a participação do trabalhador livre, ainda que lado a lado com a mão-de-obra escrava.
} 
PANIZZOLO, Claudia; BARROS, Gabriel Meneses; SOUZA, Andrea de Faria. "Hei de cumprir esses meos deveres da milhor forma possivel": indícios da presença italiana em são paulo a partir do processo disciplinar contra professor público (Brotas, 1895/1896)

para cá vieram com o objetivo de se fixar nos núcleos urbanos como artesãos, comerciantes e operários.

O operariado era composto basicamente por imigrantes que, segundo Costa e Schwarcz (2000, p. 37), trouxeram em sua bagagem, além de experiências profissionais, as ideias socialistas e anarquistas, "que irão disseminar nas duas primeiras décadas do século XX, na tentativa de melhorar as duras condições de vida a que estavam submetidos”. Além dos imigrantes, havia uma minoria constituída por brasileiros pobres e ex-escravizados que trabalhavam nas fábricas, mas o grosso desse contingente vagava pela cidade atrás de pequenos trabalhos, ou ocupando cargos como vendedores ambulantes, carregadores, carroceiros e lavadores de roupa.

A bibliografia sobre a presença do imigrante italiano na educação na Província e no Estado de São Paulo nos conta sobre o imigrante, preponderantemente, o aluno. Alguns estudos como os de Prado (2014, 2015, 2016) e Panizzolo (2016, 2018a, 2018c, 2019) privilegiam a discussão sobre a organização e funcionamento das escolas; as políticas da Itália para o envio de subsídios; as escolas italianas da capital de São Paulo como espaços de aprendizagem dos saberes elementares. Panizzolo (2018a, 2018b) destaca ainda as escolas como espaços de patriotismo, e para isto, delas foi exigido a responsabilidade em "italianizar” os que para cá vieram de uma Itália recém-unificada, e ao mesmo tempo "paulistanizar" os que aqui chegaram, que como estrangeiros eram reconhecidos e como italianos nomeados.

Mas quais outras possibilidades para pensar a relação imigração e escolarização? Este artigo tem por objetivo problematizar o exercício da docência pelo imigrante, valendo-se de um caso de processo disciplinar da Instrução Pública Paulista no ano de 1895. O texto tem por objetivo interrogar qual o lugar da docência nas pesquisas sobre história da imigração italiana em São Paulo, e a partir do processo disciplinar, localizar indícios que corroborem com a construção dessa história.

Ancorado nos referenciais da História Cultural e História da Educação, tendo a análise documental como procedimento adotado, o presente texto tem como fontes um processo disciplinar instaurado pela Diretoria da Instrução Pública, além de leis, decretos e notícia publicada na imprensa local. Toma-se de empréstimo a conceituação de tática e estratégia de De Certeau (2014). Tática como “a arte do fraco” (DE CERTEAU, 2014, p. 95), daqueles que são despossuídos de grandes poderes de compra ou de acesso, são aqueles indivíduos que são pressionados por instâncias maiores que ele, que precisam aprender a lidar com as regras estipuladas por terceiros. Segundo o próprio autor, aqueles que se utilizam da tática são aqueles que precisam operacionalizar uma série de saberes não prescritos para lidarem com as situações postas. 
PANIZZOLO, Claudia; BARROS, Gabriel Meneses; SOUZA, Andrea de Faria. "Hei de cumprir esses meos deveres da milhor forma possivel": indícios da presença italiana em são paulo a partir do processo disciplinar contra professor público (Brotas, 1895/1896)

Por sua vez, a estratégia seria esse lugar de onde emana o poder. É o lugar da hegemonia, que tenta moldar e controlar as diferentes pessoas. As estratégias são acionadas por aqueles que constituem a própria noção de "lugar", que demarcam territórios, espaços, geografias. As estratégias limitam os diferentes sujeitos por meio de prescrições, sejam elas legais ou não. $\mathrm{O}$ indivíduo ou grupo que se utiliza das estratégias almeja dar organicidade às coisas por meio de seu controle.

Para realizar esta investigação, o recorte temporal incide na última década do século XIX, mais precisamente entre 1895 e 1896, período em que foi instaurado o processo disciplinar contra o professor italiano Luigi Pericles Salmena.

O texto está organizado em três seções, na primeira são apresentados os dispositivos de controle e organização da docência criados pelo Serviço de Inspeção Escolar; na segunda seção, o processo contra o professor italiano Luigi Pericles Salmena; na terceira seção, discute-se a presença dos imigrantes italianos nas escolas públicas paulistas; e por fim, algumas considerações finais.

\section{Dispositivos de controle e organização da docência: os processos disciplinares}

A partir da Proclamação da República, o Estado de São Paulo passa a realizar uma série de reformas em vários níveis, com a preocupação de formar as novas gerações para serem os novos votantes. Para tal, se fazia mister saber ler e escrever. A docência ganha relevância, bem como um maior controle de suas atribuições, de modo a assegurar a obediência aos padrões republicanos. Fazia-se necessário conhecer, acompanhar e esquadrinhar esses professores. Dessa forma, uma série de procedimentos foram adotados, ou melhor, delimitados, por meio da Reforma da Instrução Pública de 1892/1893.

O Decreto de n⿳2 218, de 27 de novembro de 1893, instituiu o Regulamento da Instrução Pública Paulista introduzindo algumas alterações, mantendo, no entanto, parte significativa dos artigos fixados pelo Decreto no 144-B, de 30 de dezembro de 1892.

Dentre os dispositivos de controle, as questões atreladas à fiscalização das escolas, bem como dos professores, sofreram grandes mudanças, a partir do cargo dos inspetores distritais, divididos em 30 distritos (PAULO; WARDE; PANIZZOLO, 2009). Tal alteração reorganizava e hierarquizava a estrutura administrativa para o exercício das funções executivas do ensino. Nessa reestruturação, tem-se a seguinte hierarquia: Presidente do Estado, como figura central; Conselho Superior; Diretor Geral da Instrução Pública; inspetores distritais; diretores escolares - para os grupos escolares; professores. 
PANIZZOLO, Claudia; BARROS, Gabriel Meneses; SOUZA, Andrea de Faria. "Hei de cumprir esses meos deveres da milhor forma possivel": indícios da presença italiana em são paulo a partir do processo disciplinar contra professor público (Brotas, 1895/1896)

Segundo a Lei no 88 de 08 de setembro de 1892, a Inspeção Geral do Ensino no Estado de São Paulo passou a ser exercida por meio de um Conselho Superior, constituído por sete membros, sendo conduzido pelo Diretor Geral da Instrução Pública. O serviço de inspeção, instância intermediária entre o Conselho Superior e os professores, era constituído por trinta inspetores de distrito responsáveis por visitar as escolas de sua jurisdição para a fiscalização e inspeção, mantendo contato regular com diretores, professores e alunos a fim de colocar o aparelho escolar do Estado de São Paulo funcionando em sintonia com a Legislação instituída em 1892/1893 (PAULO; WARDE; PANIZZOLO, 2009).

De acordo com Reis Filho (1995), nos tempos do Império, a inspeção escolar era exercida pelas municipalidades e reduzia-se muitas vezes ao fornecimento de atestados de frequência aos professores. Por determinação da organização hierárquica instituída na administração da Instrução Pública do Estado de São Paulo, o serviço de inspeção escolar passou a ser composto por professores diplomados pela Escola Normal, e com no mínimo três anos de exercício no magistério, o que intensificou uma atuação mais profissional.

Cabe destacar outro dispositivo de controle, o Código disciplinar, seção do Regulamento de 27 de novembro de 1893, dedicada a elucidar detalhadamente os delitos e as ações passíveis de punição, que se referiam aos alunos, aos pais dos alunos, aos diretores de escola, aos funcionários e aos professores, sendo um marco no tratamento da temática, demonstrando o quanto os mandatários requeriam maior controle sobre as ações que se davam nas escolas.

No que se refere aos professores, objeto deste texto, os processos apresentavam a finalidade de verificar o ocorrido, bem como solicitar esclarecimentos adicionais em decorrência de alguma denúncia sobre o comportamento ou atitude do profissional. Há por princípio, nos processos, a ideia de ampla defesa do acusado. Ainda assim, conforme indicado por Barros (2020), os processos detinham em si caraterísticas punitivas, tendo a finalidade de controlar, orientar e indicar que a conduta do(a) acusado(a) estava em desacordo com as orientações do Estado, e o indivíduo deveria ater-se as suas funções e a forma de exercê-las.

Quem averiguava a pertinência e instaurava os processos disciplinares era o Diretor Geral da Instrução Pública, cargo ocupado por Arthur Cesar Guimarães, até a sua extinção em 1897. Era ele quem recebia as denúncias, estipulava os prazos para que os professores apresentassem suas defesas e exigia as explicações necessárias, ou ainda, requeria a arguição de outras instâncias. Em alguns casos, os processos eram endereçados ao Secretário do Ministério dos Negócios do Interior.

Antes do processo disciplinar, havia a admoestação, a repreensão e a multa aplicada pelo inspetor. Contudo, havia situações que suscitavam o processo automaticamente, como, por 
PANIZZOLO, Claudia; BARROS, Gabriel Meneses; SOUZA, Andrea de Faria. "Hei de cumprir esses meos deveres da milhor forma possivel": indícios da presença italiana em são paulo a partir do processo disciplinar contra professor público (Brotas, 1895/1896)

exemplo, o desacato ao superior hierárquico. Dentre esses delitos, um deles era passível de exoneração automática, o de inculcar valores contrários à moral e aos bons costumes nos alunos.

Na década de 1890, a questão da moralidade ganhou novos contornos, e pela primeira vez na educação definiu-se uma moralidade laica. Os pressupostos dessa "nova moralidade", ainda muito tributária da visão católica, tinham como valor o controle dos gestos e o respeito aos adultos como propagadores da verdade.

A seguir, destacamos para análise um processo disciplinar referente à inculcação de valores contrários à moral e aos bons costumes, passível, portanto, de exoneração, instaurado contra o professor italiano Luigi Pericles Salmena.

\section{O processo contra Luigi Pericles Salmena}

O processo contra Luigi Pericles Salmena, professor da cidade de Brotas, é composto por sete documentos, somando 11 páginas. Foi iniciado em dezembro de 1895 e concluído em janeiro de 1896, tempo bastante curto em comparação com outros processos (BARROS, 2020).

O processo foi incitado a partir de uma denúncia feita no jornal Gareta de Brotas, contra o "procedimento irregular e incorrecto de certo professor interino de uma das escolas públicas desta cidade” (INSTRUÇÃO PÚBLICA PAULISTA, 1896, p. 1)².

Salmena era um professor interino, ou seja, na maioria das vezes não tinha formação especializada para a docência. Os professores interinos eram contratados por meio de concurso realizado perante os inspetores de distrito, nos termos do Regimento de 1893, e lecionavam nas escolas provisórias, que tinham seu caráter precário acentuado pelo seu plano de estudo reduzido: leitura, escrita, princípios de cálculo, geografia geral e do Brasil, princípios das Constituições da República e do Estado (REIS FILHO, 1995).

Segundo Monarcha (1999) e Reis Filho (1995), no ano de 1897, praticamente metade das escolas da Instrução Pública eram ocupadas por professores interinos. A este respeito, Barros (2020, p. 148) afirma que o professor interino era compreendido, à época, como "uma espécie de mal que precisava ser tolerado até que houvesse professores formados em número suficiente para assumir todas as escolas provisórias".

A seleção desses professores se dava por prova elaborada pelo inspetor distrital e realizada por meio de uma banca avaliadora selecionada e presidida por ele. Não havia um modelo específico de avaliação, alterando-se de acordo com as necessidades, interesses e localidades. Vale ressaltar que segundo o Decreto n ${ }^{\circ} 218$, de 1893, na ausência do inspetor de distrito eram os presidentes

\footnotetext{
${ }^{2}$ O processo encontra-se Arquivo Público do Estado de São Paulo (APESP), na Caixa 4998.
} 
PANIZZOLO, Claudia; BARROS, Gabriel Meneses; SOUZA, Andrea de Faria. "Hei de cumprir esses meos deveres da milhor forma possivel": indícios da presença italiana em são paulo a partir do processo disciplinar contra professor público (Brotas, 1895/1896)

das municipalidades que exerciam a atribuição de nomear as comissões para examinarem os pretendentes às cadeiras vagas de caráter interino.

Retomando o processo, o jornal Gazeta de Brotas apresenta a denúncia sobre o professor italiano:

\begin{abstract}
Tendo sido ha muito tempo abolidos das escolas os castigos corporaes, parece que o rapazóla arvorado em professor, inflingindo as disposições legaes á respeito, tenta introduzil-os de novo na escola que lhe fazem dirigir.

$\mathrm{E}^{\prime}$ assim que obriga os meninos a conservarem-se por muito tempo de joelhos sobre espigas de milhos. Esse novo gênero de! castigo, para aqui "importado" com o improvisado professor, alem de molestar physicamente o alumno, tem mais o inconveniente de degradar-lhe o caracter [...] (INSTRUÇÃO PÚBLICA PAULISTA, 1896, p. 1).
\end{abstract}

Há alguns termos na denúncia que chamam a atenção, pois descrevem a figura docente, como inexperiente, um "rapazola", de pouco ou nenhum saber e formação, de "improvisado professor", supondo tratar-se de uma pessoa de pouca idade e de pouca experiência junto à Instrução Pública.

A abertura do processo foi feita por Antonio Marques da Costa, presidente da Câmara Municipal de Brotas. Na apresentação da denúncia, pautado na notícia de jornal, admite ser esse um fato grave e denomina que o ato fora praticado por um professor italiano, informação que não havia aparecido até então. Não apresenta todos os fatos, já que estavam contidos na notícia de jornal. Segue indicando que o inspetor do distrito já estivera na localidade em contato com o professor por outras circunstâncias e que embora tivesse conhecimento acerca da denúncia, não tomara nenhuma atitude. Especula que isso tenha se dado, talvez, pelo descrédito da parte do inspetor quanto ao relato. É exigida, por parte do Diretor Geral da Instrução Pública, a manifestação do inspetor e a defesa do professor italiano.

A estratégia utilizada na denúncia foi, além de fornecer a notícia jornalística, salientar que o fato era grave. Segundo Barros (2020), ao que parece, o intento do processo não era atingir o professor italiano, mas sim o inspetor do distrito:

O processo contra Luigi Pericles Salmena elucida a tensão que havia entre Câmara e Inspetoria, uma vez que a primeira reporta os delitos diretamente ao Diretor Geral, afirmando que o inspetor estava ciente da situação e nada fizera.

[...] O que chama a atenção é que o professor interino era uma escolha do inspetor distrital, o que faz pensar que a acusação pelo mal desenvolvimento dos trabalhos e pela agressão aos alunos, feitas pela Câmara Municipal no caso do professor Salmena, incorre em erro da própria inspetoria que não soube escolher profissional adequado para a função.

O que todos esses indicativos revelam é uma disputa entre diferentes órgãos na manutenção de seus cargos, que poderiam ser extintos a qualquer instante, por meio de alterações na legislação. (BARROS, 2020, p. 147-148). 
PANIZZOLO, Claudia; BARROS, Gabriel Meneses; SOUZA, Andrea de Faria. "Hei de cumprir esses meos deveres da milhor forma possivel": indícios da presença italiana em são paulo a partir do processo disciplinar contra professor público (Brotas, 1895/1896)

Com relação à denúncia, o inspetor distrital argumenta que pensou tratar-se de intriga local e não de um problema realmente sério. É relevante salientar que o processo foi aberto por meio da iniciativa de Antonio Marques da Costa, o presidente da Câmara Municipal de Brotas, a partir de uma denúncia noticiada no Jornal A Gažta de Brotas. Quem teria sido o denunciante? O próprio Presidente da Câmara?

A punição corporal imposta aos alunos, motivo principal da denúncia do jornal contra o professor Salmena, parece ter sido secundarizada pelo representante da municipalidade frente à conduta do inspetor distrital no documento ao Diretor Geral da Instrução Pública. Talvez o processo do professor Salmena represente as relações conflituosas entre os inspetores de distrito e as Câmaras das Municipalidades.

Para Souza (1991), as Câmaras Municipais eram acometidas de influências políticas locais e, por vezes, com relações baseadas em clientelismo político, que resultavam em indicações de professores para as escolas. Qual teria sido a expectativa de Antonio Marques da Costa frente à conclusão do processo disciplinar instaurado? Teria sido a de punição ao professor italiano ou de denúncia sobre a conduta do inspetor de distrito?

Em sua defesa, o professor italiano acionou como táticas uma série de argumentos. A primeira tática dizia respeito ao motivo de sua ação, o que o levou a punir os alunos, bem como o tempo reduzido da ação corretiva. Alegou que deixava sim, alguns alunos ajoelhados e com chapéu de burro, nunca mais do que 15 minutos, e que o fizera "por serem encorrigibeis; e principalmente porque ainda não conhecia o Regulamento da Instrução Pública.” (INSTRUÇÃO PÚBLICA PAULISTA, 1896, p. 7). Uma segunda tática empregada foi a apresentação de uma conduta revisada e muito mais branda que a do seu antecessor. Assim, alegou que os castigos mais severos já haviam sido banidos de sua prática como professor:

\footnotetext{
Quanto aos instrumentos de castigos, taes como: palmatoria de que se esqueceo de fallar o respeitavel e sensatissimo jornal "D Gazetinha de Brotas" e vara de marmello, são legados de meo antecessor, que ja bani da minha escola. [...] Faço por conhecer qos meos deveres e auxiliado sempre por $\mathrm{V}^{a} \mathrm{~S}^{\mathrm{a}}$, que sabe me fazer justiça, e honrado pela confiança dos paes de familia, que me conhecem - confiança essa que se augmenta na razão direita do aumento dos alunnos que tive e tenho presentemente, hei de cumprir esses meos deveres da milhor forma possivel. Creio que é o quanto basta para justificar-me. (INSTRUÇÃO PÚBLICA PAULISTA, 1896, p. 7-8, grifos no original).
}

A terceira tática acionada foi a de alegar desconhecimento quanto ao Regulamento da Instrução Pública. E por fim, acrescenta a confiança e o apreço da parte dos pais para respaldar sua defesa, confiança demonstrada no aumento no número de alunos. 
PANIZZOLO, Claudia; BARROS, Gabriel Meneses; SOUZA, Andrea de Faria. "Hei de cumprir esses meos deveres da milhor forma possivel": indícios da presença italiana em são paulo a partir do processo disciplinar contra professor público (Brotas, 1895/1896)

Acerca dos castigos físicos, cabe mais um esclarecimento. De acordo com o artigo 468 do Código Disciplinar contido no Decreto no 218 de 27 de novembro de 1893, os alunos do ensino primário estavam sujeitos a sofrerem as penas disciplinares de acordo com a gravidade das faltas cometidas, sendo elas, determinadas pelo prudente arbítrio dos professores e, mesmo assim, após terem sido utilizados outros recursos que se mostrassem improfícuos à mudança de comportamento dos alunos, assim, somente após esgotadas as possibilidades, os alunos ficavam sujeitos as seguintes penas:

\footnotetext{
Admoestação particular; más notas nos boletins semanais das escolas, dirigidos às pessoas que os representarem; retirada de boas notas; repreensão em comunidade; reclusão na escola, depois de concluído o trabalho diário, sob a vigilância dos professores ou adjuntos, por espaço máximo de meia hora; exclusão de prêmios escolares; exclusão do quadro de honra das escolas (SÃO PAULO, 1893).
}

Então, de fato, ou por desconhecimento ou por desacato, o professor Salmena descumpriu o Decreto vigente. Sua conduta, no entanto, não era isolada, pelo contrário, a história e a historiografia da educação são fartas em exemplos da aplicação de tais castigos até meados do século XX.

Infelizmente não foi localizado o documento que apresenta o desfecho do processo, e assim, não sabemos se o professor Luigi foi punido, demitido ou absolvido do processo.

\section{A presença dos imigrantes na escola pública paulista}

Deixaram a Itália a fim de fare l'America, expressão amplamente utilizada pelos imigrantes italianos que, traduzida literalmente, significa "fazer a América" e, semanticamente, indicava o desejo de uma vida melhor, com condições de trabalho e moradia dignos. Em meio a muitas adversidades de trabalho e moradia e às indispensáveis condições materiais para conseguir frequentar a escola, muitos pais enfrentaram árduos sacrifícios para que seus filhos estudassem, preferencialmente em uma escola italiana, ou ainda, nas escolas públicas paulistas.

Com relação às escolas italianas, no ano de 1898, o Almanaco del Fanfulla publicou a matéria intitulada As escolas italianas de São Paulo ${ }^{3}$, asseverando que as escolas italianas em São Paulo eram numerosas e deixadas quase inteiramente à iniciativa privada. A primeira escola fundada na cidade de São Paulo de que se tem notícia é a Sempre Avanti Savoia! no ano de 1887; depois, em 1889, as

\footnotetext{
${ }^{3}$ No original Le scuole italiane di S.Paolo.
} 


\section{Dialogia}

PANIZZOLO, Claudia; BARROS, Gabriel Meneses; SOUZA, Andrea de Faria. "Hei de cumprir esses meos deveres da milhor forma possivel": indícios da presença italiana em são paulo a partir do processo disciplinar contra professor público (Brotas, 1895/1896)

escolas Italiana, Regina Margherita e Giuseppe Garibaldi; até 1898 já estavam em funcionamento vinte e nove escolas privadas na cidade. Este número dobrou até 1906, alcançando 157 até $1910^{4}$.

No interior do Estado de São Paulo também foram criadas escolas italianas. As duas primeiras de que se tem notícia em funcionamento, em 1889, foram o Circolo Italiani Uniti e a Società Italiana Confederata, ambas na cidade de Campinas. Passados alguns anos, em 1908, aumentaram significativamente. Foram criadas escolas em Araraquara (2), Araras (1), Batatais (1), Botucatu (1), Brotas (1), Campinas (8), Guaratinguetá (1), Guariba (1), Jaú (1), São João de Bocaina (2), Piracicaba (1), Ribeirão Preto (7), Ribeirãozinho (1), São Carlos do Pinhal (2), São Jose do Rio Pardo (1), São Lourenço do Turvo (1). (MINISTERO DEGLI AFFARI ESTERI, 1889; 1908).

As escolas italianas no Estado de São Paulo, criadas pela iniciativa privada, foram ao longo de sua existência mantidas por parcos subsídios do governo italiano e, sob algumas condições, também por recursos do governo brasileiro e por doações da Sociedade Dante Alighieri.

A condição para receber o subsídio do governo italiano era aceitar a supervisão do régio cônsul-geral e assim receber um auxílio em dinheiro ou em livros e materiais. Aliás, esta era a modalidade de subvenção mais adotada pelo governo italiano, enviados ao Consulado ou adquiridos em São Paulo, com os fundos colocados à disposição pelo Ministério das Relações Exteriores.

O ensino oferecido nas escolas italianas em São Paulo era denominado curso elementar, organizado em duas seções, sendo a inferior composta pela $1^{\mathrm{a}}, 2^{\mathrm{a}}$ e $3^{\mathrm{a}}$ classes, e a superior, constituída pela $4^{a}$ e $5^{a}$ classes. Algumas escolas criaram, no entanto, um tipo híbrido composto pelo elementar inferior acrescido da quarta série (MINISTERO DEGLI AFFARI ESTERI,1905) ${ }^{6}$.

Devido às muitas dificuldades financeiras que geravam precárias condições de vida, muitas famílias italianas buscavam uma vaga nas escolas públicas paulistas. Panizzolo (2018c, 2019) localizou que na capital do Estado, muitas crianças italianas e descendentes estudavam nas escolas dos bairros onde residiam, ou seja, principalmente na região central cidade. Se as famílias italianas procuravam uma vaga para seus filhos nos bancos escolares da Instrução Pública na capital, inferese que também o fizessem no interior do Estado. Mas o mapeamento da presença dessas crianças nas escolas públicas paulistas ainda precisa ser realizado.

Se de um lado, por meio das fontes e das bibliografias, encontramos as crianças frequentando as escolas públicas, o que sabemos sobre o exercício do magistério pelos imigrantes?

\footnotetext{
${ }^{4}$ É preciso esclarecer que os dados colhidos até o momento não permitem afirmar se as 157 escolas estavam todas funcionando até 1910 ou se algumas já haviam encerrado os serviços.

${ }^{5}$ A respeito dos subsídios enviados pelo governo brasileiro e pela Sociedade Dante Alighieri consultar $O$ processo escolar entre italianos e seus descendentes: a escola italiana em São Paulo, no século XIX e início do século XX (PANIZZOLO, 2018b).

${ }^{6}$ No original Elenco delle scuole italiane nello stato di San Paolo nel 1905.
} 
PANIZZOLO, Claudia; BARROS, Gabriel Meneses; SOUZA, Andrea de Faria. "Hei de cumprir esses meos deveres da milhor forma possivel": indícios da presença italiana em são paulo a partir do processo disciplinar contra professor público (Brotas, 1895/1896)

O que conhecemos sobre o professor Salmena? Para além de seu processo, pouco sabemos sobre o professor. O professor não consta dos inventários de alunos da Escola Normal de São Paulo. Talvez tenha estudado fora da capital.

Outra possibilidade é de que o professor já tivesse vindo para o Brasil com o Curso Normal ou o equivalente realizado na Itália. Segundo Panizzolo (2019), poucos professores que trabalharam nas escolas italianas na cidade de São Paulo eram formados. A maioria não tinha formação específica, apenas havia cursado o ginasial ou o curso elementar. Outra possibilidade, a mais provável, é que de fato o professor não tivesse formação, por isto concorreu à vaga de professor interino e não à outra vaga que exigisse formação específica.

\section{Considerações finais}

O processo contra o professor Luigi Pericles Salmena nos dá pistas acerca das disputas pelo poder envolvendo as Câmaras Municipais e os inspetores de distrito, representantes da Instrução Pública. Apontam ainda para as dificuldades enfrentadas pelos inspetores no cumprimento de suas funções, nas visitas de inspeção às escolas, com regularidade e observância das determinações legais. Também revela muito mais do que as tensões hierárquicas que permeavam a Instrução Pública Paulista naquele período. Indica a questão da moralidade na escola pública, o olhar da sociedade para com as ações feitas pelo professor em classe, e o debate sobre os castigos corporais. Não se pode perder de vista que esses diferentes aspectos retratam uma instituição que estava se revitalizando, se reorganizando e ganhando relevância e projeção entre a população.

O processo contra o professor Luigi Pericles Salmena nos suscita muitas perguntas a partir da presença, bastante inédita, de um professor italiano exercendo o magistério, na condição de interino no interior do Estado de São Paulo, ainda no início do período de intenso fluxo imigratório, consagrado pela historiografia como da "grande imigração". Como Salmena, provavelmente existiram, nesse período, outros professores a exercer o magistério. Onde residiam? Onde lecionaram? Qual sua formação? O professor Salmena é um convite para a continuidade das pesquisas sobre a presença dos imigrantes italianos como alunos e como professores nas escolas da Instrução Pública Paulista.

\section{Referências}

BARROS, G. M. "Há mister de saber que os subalternos também têm o direito de ser respeitados": processos disciplinares contra professores paulistas (1887-1896). Guarulhos: UNIFESP, 2020. 182.f. Dissertação (mestrado em Educação) - Universidade Federal de São Paulo, Escola de Filosofia Letras e Ciências Humanas, Guarulhos, São Paulo, 2020. 


\section{Dialogia}

PANIZZOLO, Claudia; BARROS, Gabriel Meneses; SOUZA, Andrea de Faria. "Hei de cumprir esses meos deveres da milhor forma possivel": indícios da presença italiana em são paulo a partir do processo disciplinar contra professor público (Brotas, 1895/1896)

COSTA, A. M. da; SCHWARCZ, L. M. 1890 - 1914; no tempo das certezas. São Paulo: Companhia das Letras. (Virando séculos). 2000.

COSTA, E. V. da. Da monarquia à república; momentos decisivos. $7^{a}$ ed. São Paulo: UNESP, 1999. (Biblioteca Básica).

DE CERTEAU, M. A invenção do cotidiano: 1. Artes de fazer. Tradução de Ephraim Ferreira Alves. Petrópolis: Vozes, 2014.

MONARCHA, C. Escola Normal da Praça: o lado noturno das luzes. Campinas: Editora da Unicamp, 1999.

PANIZZOLO, C. Italianizar os brasileirinhos, paulistanizar os italianinhos: um estudo sobre os livros de leitura que circularam nas escolas em São Paulo no início do século XX. In: CASTRO, C. A.; CASTELLANOS, S. L.V. História da escola; métodos, disciplinas, currículos e espaços de leitura. Maranhão: EDFUMA, 2018a, p. 100- 125.

PANIZZOLO, C. Livros de leitura, dizeres e fazeres da escola primária étnica italiana no Brasil entre fins do século XIX e início do século XX: o estudo do livro Piccolo Mondo, letture per le scuole elementari. In: XI Congresso Luso- Brasileiro de História da Educação. Porto: Centro de investigação transdisciplinar cultura, espaço e memória. 2016, Porto. Anais do XI Congresso Luso- Brasileiro de História da Educação. Porto: Centro de investigação transdisciplinar cultura, espaço e memória. 2016.

PANIZZOLO, C. O jornal Fanfulla e a escola étnica italiana em São Paulo: ensinar a ler, escrever, calcular e a ser italiano (1893-1910). In: XIII Congresso Ibero Americano de História da Educação, 2018, Montevideu. Anais do XIII Congresso Ibero Americano de História da Educação, 2018. Montevideu, 2018b, s/p.

PANIZZOLO, C. O processo escolar entre italianos e seus descendentes: a escola italiana em São Paulo (fins do século XIX e início do século XX). Relatório de pesquisa FAPESP. Bolsa de Pesquisa no ExteriorBPE, 2019.

PANIZZOLO, C. O processo escolar entre italianos e seus descendentes: a escola italiana em São Paulo, no século XIX e início do século XX. In: LUCHESE, T. Â. (org). Escolarização, culturas e instituiçoes; escolas étnicas italianas em terras brasileiras. Caxias do Sul: EDUCS, 2018c.

PRADO, E. M. Polêmicas no ensino da Língua Portuguesa nas escolas elementares de estrangeiros na cidade de São Paulo. In: DOMINGUES, A. S. (Org.). Lingua, memória e nação. Jundiaí: Paco Editorial, v. 12, p. 31-50. 2016.

PRADO, E.M. Acondicionamento das escolas de Primeiras letras paulistas no período que compreende os anos de 1877 a 1910. In: LUCHESE, T. A. (Org.). História da escola dos imigrantes italianos em terras brasileiras. Caxias do Sul: EDUCS, v. 1, p. 90-114. 2014.

PRADO, E.M. As escolas elementares paulistas e seus alunos estrangeiros na passagem do século XIX para o XX. Revista HISTEDBR On-line, v. 15, p. 259-269, 2015. Disponível em: https://periodicos.sbu.unicamp.br/ojs/index.php/histedbr/article/view/8641182/8689. Acesso em 25 de março de 2021. 
PANIZZOLO, Claudia; BARROS, Gabriel Meneses; SOUZA, Andrea de Faria. "Hei de cumprir esses meos deveres da milhor forma possivel": indícios da presença italiana em são paulo a partir do processo disciplinar contra professor público (Brotas, 1895/1896)

PAULO, M.A.R.; WARDE, M.J; PANIZZOLO, C. O serviço de inspeção estabelecido no Estado de São Paulo pela Reforma da Instrução Pública de 1892/1893. Cadernos de História da Educação. Uberlândia (MG), vol.8, n.02, jul/dez. 2009.

REIS FILHO, C. dos. A educação e a ilusão liberal: origens da Escola Pública Paulista. Campinas: Autores Associados, 1995. (Coleção memória da educação).

SOUZA, R. F. de. Classes populares e educação popular na primeira República: problemas, valores e lutas. Campinas: UNICAMP, 1991. 190.f. Dissertação (mestrado em Educação) - Universidade Estadual de Campinas, Faculdade de Educação, Campinas, São Paulo, 1991.

\section{Fontes}

ALMANACO DEL FANFULLA. Le scuole italiane di S. Paolo.1898. p.397-8. In: Archivio Storico Diplomatico del Ministero degli Affari Esteri, Archivio Scuole, 1889-1910, b.341.

INSTRUÇÃO PÚBLICA PAULISTA. ARQUIVO PÚBLICO DO ESTADO DE SÃO PAULO. Processo disciplinar Professor Luigi Pericles Salmena, 1896, (Caixa 4998).

MINISTERO DEGLI AFFARI ESTERI. Annuario delle scuole colonial per l'anno finanziario e scolastico 1888-89. Roma: Tipografia di Gabinetto del Ministero degli affari esteri, 1889.

MINISTERO DEGLI AFFARI ESTERI. Elenco delle scuole italiane nello stato di S. Paolo,1905. In: Archivio Storico Diplomatico del Ministero degli Affari Esteri, Archivio Scuole, 1889-1910, b.314.

SÃO PAULO. Lei 88, de 08 de setembro de 1892. Disponível em: https://www.al.sp.gov.br/repositorio/legislacao/lei/1892/lei-88-08.09.1892.html. Acesso em 25 de março de 2021.

SÃO PAULO. Decreto 144-B, de 30 de dezembro de 1892. Disponível em: https://www.al.sp.gov.br/repositorio/legislacao/decreto/1892/decreto-144B-30.12.1892.html. Acesso em 25 de março de 2021.

SÃO PAULO. Decreto 218, de 27 de novembro de 1893. Disponível em: https://www.al.sp.gov.br/repositorio/legislacao/decreto/1893/decreto-218-27.11.1893.html. Acesso em 25 de março de 2021. 